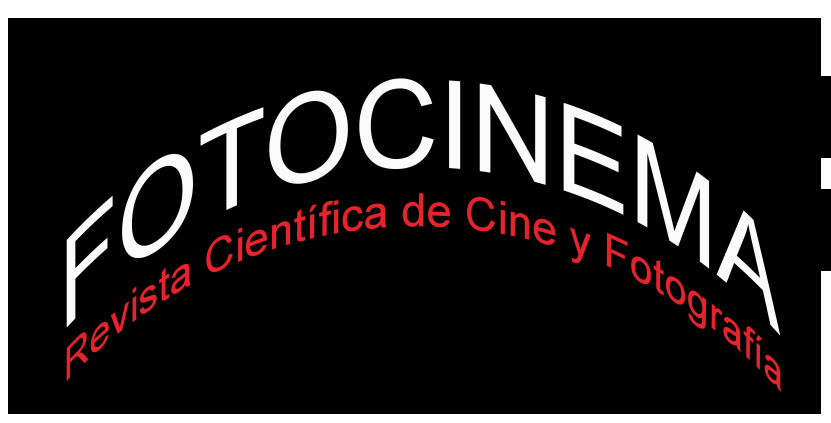

\title{
EL SONIDO DE LA MUERTE: LA (IM)POSIBLE FORMULACIÓN DE LO MONSTRUOSO
}

\section{SOUND OF HORROR: THE (IM)POSSIBLE FORMULATION OF THE MONSTROUS}

\author{
Rubén Higueras Flores \\ Universidad Complutense de Madrid, España \\ rubhigue@ucm.es
}

\section{Résumé:}

El presente ensayo pretende abordar la singular formulación de determinados rasgos temáticos $\mathrm{y}$ recursos expresivos propios del cine de terror que la película El sonido de la muerte (1965), dirigida por José Antonio Nieves Conde, lleva a cabo. Con tal fin, optaremos por el análisis textual y del discurso como herramienta metodológica, pues permitirá que nos centremos en las particularidades del texto fílmico. El diálogo que el presente largometraje establece con su contexto histórico nos obligará a referirnos a este último en algunas ocasiones. Realizada en un período de su carrera en el que el cineasta acomete proyectos de encargo para subsistir económicamente, el filme del que nos ocuparemos conforma uno de los mejores ejemplos de la solvencia de su labor como realizador y narrador. La esquiva fisicidad de la monstruosa amenaza que pone en riesgo la vida de los protagonistas ocasiona un vacío figurativo que conlleva el subrayado de los mecanismos formales mediante los que opera la enunciación.

\begin{abstract}
:
The present essay tries to address the unique formulation of certain thematic features and expressive resources characteristics of the horror films that the film Sound of Horror (1965), directed by José Antonio Nieves Conde, carries out. To this end, we will chose the textual analysis and discourse as methodological tool, since it will allow us to focus on the particularities of the film. Carried out in a period of his career in which the filmmaker undertakes custom projects to survive financially, the film we will be dealing with is one of the best examples of the solvency of his work as a director and narrator. The elusive physicality of the monstrous threat that puts the lives of the protagonists at risk causes a figurative void that entails the underlining of the formal mechanisms through which the enunciation operates.
\end{abstract}

Palabras clave: Cine español; cine de terror; ciencia ficción; Nieves Conde

Keywords: Spanish cinema; horror cinema; science fiction; Nieves Conde 
Cómo citar: Higueras Flores, R. (2018). El sonido de la muerte: La (im)posible formulación de lo monstruoso. Fotocinema. Revista científica de cine $y$ fotografía, no $\mathrm{n}^{\mathrm{O}}$, pp. 335-349. Disponible: http://www.revistas.uma.es/index.php/fotocinema/ DOI: http://dx.doi.org/10.24310/Fotocinema.2017.voi16

\section{Introducción y metodología}

El presente ensayo pretende abordar la singular formulación de determinados rasgos temáticos y recursos expresivos propios del cine de terror que la película El sonido de la muerte (1965), dirigida por José Antonio Nieves Conde, lleva a cabo. Con tal fin, optaremos por el análisis textual y del discurso como herramienta metodológica, pues permitirá que nos centremos en las particularidades del texto fílmico, lugar de intersección entre los diversos condicionantes históricos y su lógica discursiva. El diálogo que el presente largometraje establece con su contexto histórico nos obligará a referirnos a este último en algunas ocasiones. Realizada en un período de su carrera en el que el cineasta acomete proyectos de encargo para subsistir económicamente, el filme del que nos ocuparemos conforma uno de los mejores ejemplos de la solvencia de su labor como realizador y narrador. La esquiva fisicidad de la monstruosa amenaza que pone en riesgo la vida de los protagonistas ocasiona una anomalía representacional en la escritura fílmica, efectuándose un subrayado de los mecanismos formales mediante los que opera la enunciación, que adquieren un inusitado protagonismo ante el vacío figurativo.

\section{Cuestiones historiográficas y de producción}

Tras la aciaga experiencia de El inquilino (1957), que se saldó con el secuestro del filme y la sumisión del texto a los cambios impuestos por la censura, la carrera de José Antonio Nieves Conde optaría por el sendero de la subsistencia profesional. La finalidad pecuniaria constituiría el principal 
objetivo del ejercicio de su profesión a partir de entonces, asumiendo buena parte de los encargos que le llegaban por parte de productores como José Frade o Arturo González. "Tuve que seguir caminando por la ruta que recorren la mayoría de los profesionales: casi nunca se hace lo que uno propone, sino lo que le ofrecen" (Llinás, 1995, p. 114), afirmó el cineasta años más tarde. De este ecléctico grupo de filmes, en los que el realizador transitó por géneros tan disímiles como la comedia -Don Lucio y el hermano Pío (1960), Las señoritas de mala compañía (1973)—, el melodrama -Casa manchada (1975), Volvoreta (1976) - o el thriller —El diablo también llora (1965), Marta (1971)—, probablemente sea El sonido de la muerte (1965) el más afortunado de ellos merced a la sencillez de su planteamiento y los acertados recursos narrativos y formales movilizados por Nieves Conde, optimizando, como veremos, la escasez presupuestaria del filme para jugar estratégicamente con la sugestión espectatorial, el fuera de campo, el montaje y los efectos de sonido, entre otros resortes.

Producida por Zurbano Films y rodada entre el 3 de mayo y el 5 de junio de 1965 en la madrileña localidad de La Cabrera (exteriores) y en los estudios de Samuel Bronston (interiores), El sonido de la muerte ${ }^{1}$ contó con un presupuesto de tres millones de pesetas, incluyendo la participación en la producción de un grupo americano de "pequeños inversionistas (...) que se conformaban con modestos tantos por ciento". Según cuenta Carlos Aguilar, durante la presentación del largometraje en la edición de 1982 del Festival de Cine Imaginario y de Ciencia-Ficción de Madrid (IMAGFIC), programado dentro de una retrospectiva dedicada al cine fantástico español, Nieves Conde apuntó una de las causas que impelió a ese colectivo americano a embarcarse en la producción de la presente película: “aprovechar apresuradamente los insignificantes restos del cuantioso presupuesto de una superproducción norteamericana recién rodada en nuestro país, Battle of the Bulge (La batalla de las Ardenas, 1965), de Ken Annakin, de cara a obtener una película de Serie B apta para consumo televisivo, desbloqueándose así un

\footnotetext{
${ }^{1}$ La película fue originalmente titulada El sonido de hace un millón de años, que mudó después en El sonido prehistórico para dar paso, finalmente, a su título definitivo.
} 
dinero administrativamente retenido en España” (Aguilar, 1997, p. 605). En la escritura del guion, junto con el propio director y del productor español (Gregorio Sacristán de Hoyos), participarían dos nombres recurrentes del cine de género de bajo presupuesto: Gregg G. Tallas (probablemente fue Tallas quien propuso ubicar la acción del filme en su Grecia natal) y Sam X. Abarbanel, quienes ya habían colaborado en el largometraje Prehistoric Women (1950), escrito por ambos, con el primero ocupando la silla de director y el segundo ejerciendo de productor asociado. 3 Pese al reducido presupuesto del proyecto, este logró arroparse de la labor de algunos insignes técnicos de nuestro cine, algunos de los cuales ya habían trabajado con Nieves Conde o volverían a hacerlo con posterioridad: Manuel Berenguer - Balarrasa (Nieves Conde, 1950) - como director de fotografía, Margarita de Ochoa - colaboradora habitual del cineasta: Senda ignorada (1946), Surcos (1951), Los peces rojos (1955), El inquilino (1957), Don Lucio y el hermano Pío- encargándose del montaje, Gil Parrondo y Luis Pérez Espinosa -que ya se habían puesto a las órdenes del director en Los peces rojos- haciendo lo propio con los decorados y Román Calatayud —Calabuch (Luis García Berlanga, 1956), Marta - responsabilizándose de la ambientación, a los que se unía un todavía no consagrado Luis de Pablo - La caza (Carlos Saura, 1966), El espíritu de la colmena (Víctor Erice, 1973) - a cargo de la música.

La coyuntura histórica resultaba propicia para un proyecto como el que nos ocupa, pues el cine de género europeo atravesaba una de sus etapas más felices y fértiles, que se alargaría durante la década de los setenta, con propuestas que recurrían a moldes argumentales y estéticos foráneos con afán mimetizador en pos de la rentabilidad en taquilla. En efecto, El sonido

\footnotetext{
${ }^{2}$ La coproducción era una fórmula recurrente en la época de realización de El sonido de la muerte: ese mismo año, Mario Bava realiza Terror en el espacio (Terrore nell spazio, 1965) con capital italiano y español. Posteriormente, Jesús Franco filma la hispanofrancesa Miss Muerte (1966), Santos Alcocer recurre a capital norteamericano para rodar El coleccionista de cadáveres (1966) y Mel Welles (bajo el seudónimo Ernst von Theumer) acomete La isla de la muerte (1966), coproducción entre España y Alemania del Oeste.

3 Abarbanel, estadounidense de nacimiento, terminaría afincado en nuestro país, donde participaría en los libretos de Un verano para matar (Antonio Isasi-Isasmendi, 1972) y El último día de la guerra (Juan Antonio Bardem, 1970), que también produjo, al igual que Persecución hasta Valencia (Julio Coll, 1968).
} 
de la muerte se nutre parasitariamente del esquema narrativo arquetípico de las monster movies cultivadas con asiduidad por la serie B estadounidense (especialmente, desde la década de los cincuenta), a medio camino entre el horror y los planteamientos de la ciencia ficción. Así, en el filme encontramos una premisa argumental de probada solvencia: protagonismo de un colectivo humano de cierta heterogeneidad compositiva (los personajes se reducen a arquetipos de nula profundidad psicológica, notoriamente pasivos en el caso de las dos féminas, que desempeñan el manido rol de damiselas en apuro a la espera de ser rescatadas por sus compañeros varones) 4 encerrado en un reducido espacio y cercado por una amenaza sobrenatural de naturaleza monstruosa.

\section{Marco conceptual: En torno a lo fantástico y lo monstruoso}

En El cine fantástico y sus mitologías, Gérard Lenne define lo fantástico como "la confusión (en el sentido preciso, matemático) de la imaginación y de la realidad, el choque de lo real con lo imaginario" y la "intrusión de la anormalidad en la normalidad», subrayando la necesidad de «la reconstrucción más exacta posible (ambiente, intriga, psicología) de un universo que no sea copia del mundo existente, sino terreno de encuentro de lo imaginario y lo real: lo que puede llamarse un lugar poético», puesto que “lo fantástico no podría existir sin credibilidad” (Lenne, 1974, p. 16).

Por su parte, Herrero Cecilia (2000, p. 50) apunta que

[1]o fantástico moderno pretende producir en el ánimo del lector un efecto de inquietante extrañeza ofreciéndole una historia inscrita en el marco de la vida ordinaria donde, de forma inesperada, se van a confundir o mezclar las fronteras entre lo natural y lo sobrenatural, lo racional y lo suprarracional, entre lo vivido y lo soñado, entre el mundo de los vivos y el mundo de los muertos. Esto quiere decir que el orden de la vida ordinaria (lo que

\footnotetext{
4 El sonido de la muerte reúne en pantalla a dos actrices que se convertirían en iconos del cine de género europeo: la malograda Soledad Miranda, una de las musas de Jesús Franco - Las vampiras (Vampyros Lesbos, 1973) - , e Ingrid Pitt, que cobraría popularidad con sus trabajos para Hammer Films en The Vampire Lovers (Las amantes del vampiro, Roy Ward Baker, 1970) y Countess Dracula (La condesa Drácula, Peter Sasdy, 1971).
} 
consideramos natural y racional) queda alterado, transgredido o cuestionado por la sorprendente aparición o intromisión de un fenómeno extraño e inexplicable desde una perspectiva «racionalista» (Herrero Cecilia, 2000, p. 50).

La normalidad es, por tanto, requisito indispensable para que hablemos de lo fantástico: para que algo subvierta el orden, es necesario que este exista previamente. De igual manera, lo monstruoso representa una alteridad, una otredad que actúa como oposición a un modelo de referencia entendido como normal. La irrupción de lo anormal, de lo que excede de los límites de lo normativo, produce desconcierto en un observador que se autoproclama y reconoce como modelo de referencia de lo normal, para quien lo heterogéneo supone la probabilidad de una amenaza. Como afirma Ocampo Ramírez (2013, p. 21), "la cultura occidental ha delimitado bien sus monstruos para caracterizar y mostrar con ellos lo desviado, lo extraño, lo imperfecto, lo raro, lo anómalo, así como lo maravilloso, lo asombroso y lo extraordinario; tanto en lo espiritual, psicológico y moral, como en lo físico, lo social, lo político”. El establecimiento del marco conceptual en el que se mueve lo determinado como normal fue producto de la concepción científica del mundo de la Ilustración, que "suministra una norma de lo natural que proporciona el espacio conceptual necesario para lo sobrenatural, aunque considere ese espacio como el de la superstición” (Carroll, 2005, p. 57).

A pesar de las discrepancias entre las copiosas teorías en torno a lo fantástico, todas poseen un denominador común: consideran que la introducción del elemento fantástico en la ficción representa un desafío "a la experiencia, a la racionalidad y a la lógica" (Prédal, 1970, p. 8); es decir, a la mentalidad racionalista del sujeto moderno. Podríamos, por tanto, calificar esta ruptura del orden reconocido como el elemento constituyente y esencial del fantástico. Se opera, así, una puesta en cuestión de la soberanía de la razón evidenciando sus carencias y límites. 5

\footnotetext{
5 Como señala Herrero Cecilia (200o, p. 51), "es significativo que el género de lo fantástico moderno haya surgido precisamente en la época romántica como reacción espiritual e irónica frente al absolutismo de la razón crítica y la visión positivista y desmiraculizada del mundo".
} 
En este sentido, El sonido de la muerte escenifica la contraposición entre la ciencia (representada por unos arqueólogos) y la superstición —el personaje de Calliope (Lola Gaos), la oriunda ama de llaves-. Sobre la invisibilidad del monstruo, los personajes únicamente pueden formular hipótesis: "Tal vez absorba los colores que le sirven de fondo. Tan deprisa que al momento se hace invisible", conjetura uno de ellos. Esta premisa aproxima el filme al género de ciencia-ficción, cuyos argumentos plantean hipótesis plausibles (al menos, dentro de la propia ficción que erigen), justificándose desde un punto de vista científico los componentes irreales. Sin embargo, El sonido de la muerte se decanta por el sugerente terreno de lo maravilloso (según la noción de Todorov) ${ }^{6}$ : ante la imposibilidad de explicar racionalmente la situación en que se hallan, los protagonistas terminan asumiendo la contingente existencia de lo sobrenatural. Así, la cueva de la que emana la letal amenaza representa el espacio de lo misterioso, una conexión con lo más profundo de la Tierra y lo atávico (vínculo del presente largometraje, junto a la irrepresentabilidad de lo monstruoso y la atmósfera opresiva, con la esencia lovecraftiana) en la que se hallan resquicios de lo ancestral ajenos a los efectos de la civilización.

\section{Monstruosidad}

Como hemos indicado, El sonido de la muerte se pliega a convenciones genéricas de probada solvencia comercial, si bien su irrupción en el panorama cinematográfico es ligeramente tardía, ya que la producción de monster movies había experimentado su esplendor en la década de los cincuenta, decayendo después su presencia en las pantallas. Así, la película de Nieves Conde representa una suerte de doble anacronismo en su fecha de producción, una rareza tanto por su recuperación de un modelo fílmico en desuso como por formar parte de esa suerte de prólogo, iniciado con Gritos en la noche (Jesús Franco, 1961), a la caudalosa producción de cine fantástico

\footnotetext{
${ }^{6}$ Afirma Todorov (1980, p. 31): si el lector "decide que es necesario admitir nuevas leyes de la naturaleza mediante las cuales el fenómeno puede ser explicado, entramos en el género de lo maravilloso."
} 
que la cinematografía española cultivaría con decisión a partir de 1968.7 Sin embargo, esta condición no es la única posible justificación del culto que ha merecido el filme entre determinados círculos cinéfilos afines al fantástico. Para rastrear los motivos de este prestigio, hemos de dirigir nuestra atención hacia una de las constantes de la monster movie: la desagradable mostración de una figura monstruosa en pantalla, que provoca repugnancia en el espectador y su instintivo rechazo hacia ella. Contraviniéndola, la prehistórica criatura de El sonido de la muerte no es concretada figurativamente (el espectador solamente llegará a percibir su traslúcida silueta en contados planos de escasa duración, así como su figura en un segundo plano visual mientras es pasto de las llamas), siendo así privada de una de sus características constitutivas esenciales: su monstruosa apariencia. ${ }^{8}$ Esta opción creativa se encuentra en consonancia con el reducido presupuesto del filme (la artesanía de los efectos especiales certifica la penuria presupuestaria con la que tuvo que lidiar el equipo del filme). ${ }^{9}$ Nieves Conde, generalmente crítico con su propia obra, recordaba gratamente el presente filme merced a los retos técnicos y creativos que su rodaje le planteó: “A mí me divirtió mucho hacerla. Creo que a todos los directores siempre nos agrada hacer una historia de este tipo, porque plantea problemas técnicos que sólo se pueden resolver a base de ingenio, como en los primitivos tiempos del cine". ${ }^{10}$

Ya desde el genérico, una amenaza intangible es esbozada: los intérpretes principales son presentados mientras sus respectivos personajes huyen de un peligro cuya representación se esquiva, generando una situación de peligro y de suspense sin que se concrete la causa. Este será el principal escollo para la enunciación: comunicar al espectador la presencia en pantalla de una suerte de animal antediluviano que se sirve de su invisibilidad para atacar a los

\footnotetext{
7 El éxito de La marca del hombre lobo (Enrique López Eguiluz, 1968) tres años después supondría el inicio de la edad de oro del fantaterror español.

${ }^{8}$ Se niega de esta manera esa suerte de espectáculo de la monstruosidad que constituye uno de los motivos de disfrute escópico espectatorial de las monster movies.

9 Según el director, "los efectos especiales se hicieron a base de espejos, directamente en el rodaje y no en laboratorio" (Llinás, 1995, p. 121).

10 Asimismo, el director afirmaba que esta era su película "en que la música mejor se entronca con el alma del film" (Llinás, 1995, p. 121).
} 
incautos humanos, rescatado del sueño eterno por la explosión perpetrada por estos últimos en su búsqueda de un tesoro. El empleo del sonido deviene instrumento básico para tal fin: el ruido producido por los pasos de esta entidad monstruosa acúsmetra ${ }^{11}$ y los rugidos que profiere al atacar a sus víctimas serán los dispositivos sonoros acúsmetros (su fuente sonora no es visible para el espectador) movilizados para que el espectador infiera su presencia en el interior del campo visual o en sus aledaños, aunque su fisonomía no se represente mediante códigos visuales.

Un precedente fílmico emerge como ineludible referente de El sonido de la muerte. Nos referimos al ciclo de películas de terror producidas por Val Lewton entre 1942 y 1946 para RKO Pictures, caracterizadas por el empleo de la sugerencia en lugar de optar por una explícita mostración (al contrario que el cine fantástico de la Universal cuyo éxito comercial pretendía replicar), el recurso a la oscuridad para la creación de una desasosegante atmósfera, el empleo sistemático de la elipsis en cuanto mecanismo narrativo y la instauración del fuera de campo como espacio privilegiado en el que ubicar la amenaza de naturaleza indeterminada que acecha a los protagonistas (así como todo aquello irrepresentable en pantalla; por ejemplo, los momentos de mayor violencia), estimulando el papel del espectador a la hora de "rellenar" aquellos pasajes textuales y espacios diegéticos cuya representación ha sido negada por la enunciación.

Mas regresemos al filme de Nieves Conde. Ante la imposibilidad de mostrar a la criatura, durante sus furiosos ataques la cámara se centra en la figura humana violentada, retratando sus movimientos espasmódicos al intentar huir o defenderse y las heridas letales que sobre su cuerpo se infringen. Frente a la incorporeidad del monstruoso agresor, una acentuada hipervisibilidad (rayana en el gore) y fisicidad de la violencia ejercida sobre el cuerpo humano, presentada mediante un abrupto montaje analítico y planos cercanos (primeros planos, planos medios o, incluso, planos de detalle) que representan una ruptura en la tónica escalar del filme (el

\footnotetext{
${ }^{11}$ Como recoge García Jiménez (1993, p. 101), “acusmático es, por consiguiente, el sonido que se percibe sin ver la causa o fuente de donde proviene".
} 
protagonismo coral conlleva la recurrencia de planos de conjunto que recogen la interacción del grupo de personajes en pantalla) que configura una agresión visual al espectador (F. 1, 2, 3, 4, 5, 6, 7, 8).
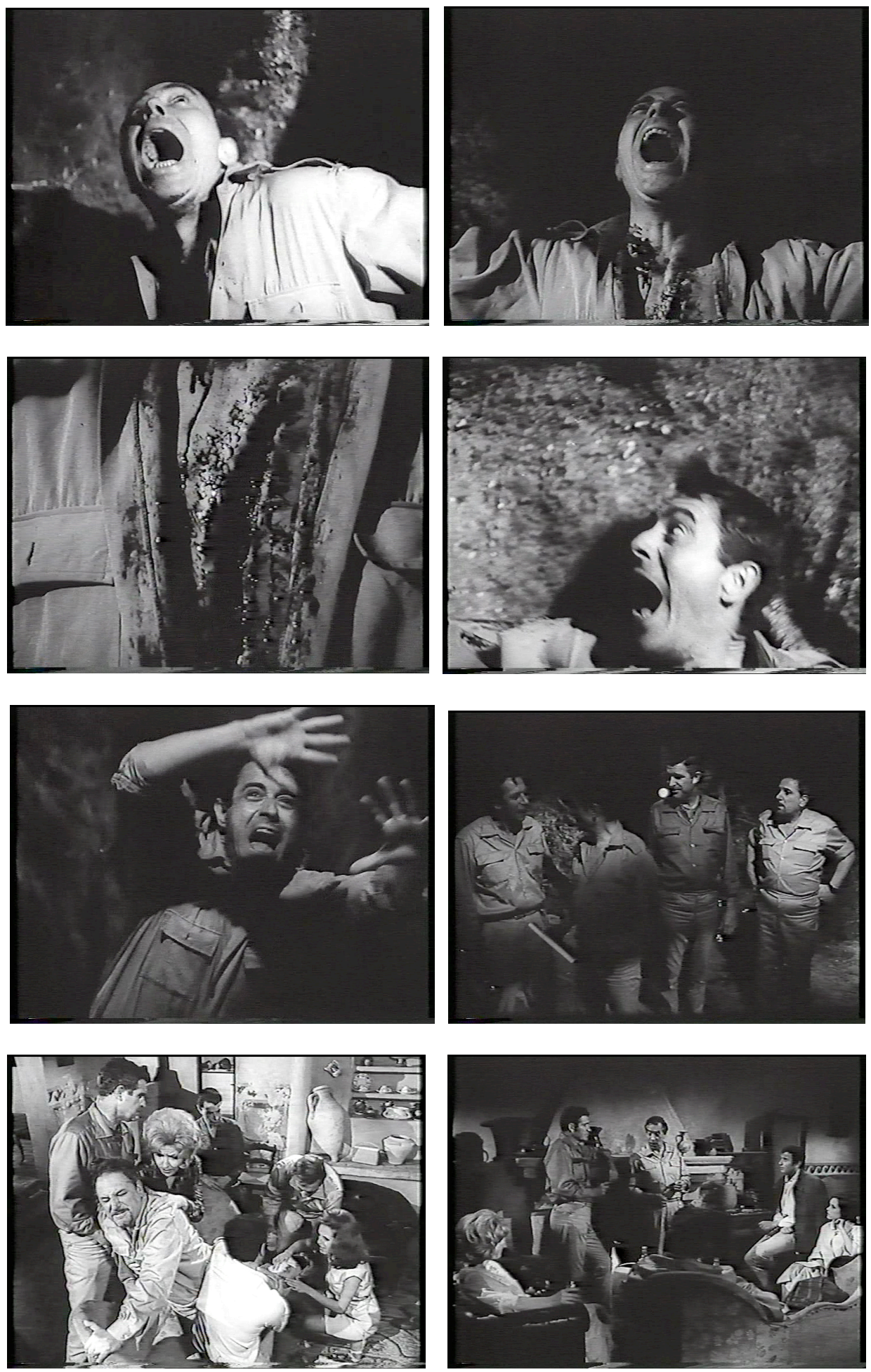

F1-F8: El sonido de la muerte (1965), José Antonio Nieves Conde 
Este vacío figurativo implica el subrayado de los mecanismos enunciativos y formales movilizados por la enunciación, que adquieren una especial relevancia ante una imagen despojada de fisonomía. Tempranamente, la cámara se emancipa de su dependencia de lo antropomórfico. Al final de la primera secuencia, la enunciación se manifiesta ostentosamente para ofrecer información privilegiada al espectador: la cámara abandona a los personajes, que salen de campo, para dirigirse hacia un elemento cuya presencia ha pasado desapercibida para aquellos y que constituye la génesis de la amenaza sobrenatural que les acechará poco después. Se trata de un segundo huevo surgido de la explosión (el primero obra en poder de los personajes), de cuyo interior brota una extraña masa que se torna invisible instantes después. No será esta la única ocasión en que la enunciación suministre al público información en exclusiva: la amenaza del huevo que reposa en la casa en que se encuentran los personajes es recordada avanzado el metraje con el mismo proceder (el alejamiento de la cámara respecto de los personajes para dedicar el protagonismo del plano al cuerpo ovalado).

La invisibilidad de la amenaza conlleva que los personajes del filme parezcan estar siendo asediados por recursos léxico-gramaticales propios del lenguaje cinematográfico. La lectura espectatorial de los planos ha de experimentar un desplazamiento semántico: lo que podría tratarse de planos descriptivos (de lugar, de ambiente) han de ser interpretados como planos de seguimiento de una amenaza invisible e inasible para el dispositivo cinematográfico. En una determinada secuencia, la cámara asume el punto de vista de la criatura. La imposibilidad de representación del peligro empuja a subjetivar el único procedimiento formal capaz de certificar visualmente la efectiva presencia del agresor.

En consecuencia, la representación de la monstruosidad se sustenta en el quiebre de la habitual complementariedad entre las bandas de sonido y de imagen: la irrupción de rugidos o sonidos de pisadas en la primera no es correspondida por la representación en pantalla de la fuente sonora (el animal prehistórico), en cuyo lugar encontramos una carencia representacional que la cámara parece obviar en ocasiones al activar los 
mecanismos prototípicos de seguimiento del actante diegético a pesar de su no formalización plástica.

\section{Alegorías}

El sonido de la muerte reincide en un motivo temático esencial en la obra del director segoviano: el encierro de los personajes en unos espacios interiores que les sirven de refugio de un exterior amenazante y dañino — cfr. Angustia (1947)—. Los protagonistas están sometidos a la presión de un entorno coercitivo regido por una nociva realidad políticosocial. Esta constante temática del cine de Nieves Conde aparece reformulada en el presente largometraje bajo la pátina de lo fantástico, acorde con la clave genérica en la que se inscribe. El exterior amenazador adquiere aquí la apariencia de un monstruo prehistórico con el poder de la invisibilidad, lo que origina que todo espacio externo represente un potencial riesgo mortal para los personajes.

Conviene recordar que el presente largometraje se produce a mitad de la década de los sesenta, en pleno proceso aperturista, iniciado después de que el gobierno de España asuma que el modelo autárquico terminaría sumiendo al país en la bancarrota y remita un Memorándum al Fondo Monetario Internacional en 1958, que sería convertido en Ley el 27 de julio del año siguiente y que funcionaría como base del Plan de Estabilización Económica y Social que perseguía la modernización económica del país. Junto con esta planificación se adoptaron una serie de medidas dirigidas a favorecer el crecimiento exponencial del turismo en el país, tales como la liberalización del control de divisas o la agilización de los trámites de visados y aduanas, además de otras destinadas a mejorar la imagen exterior de la dictadura franquista entre los europeos, como la Ley de Prensa de 1966 o la integración del país en organismos internacionales.

Si atendemos a este contexto, El sonido de la muerte podría leerse como la escenificación alegórica de la modernizadora, a la par que traumática, experiencia que para los españoles supuso el aperturismo tras dos décadas de 
aislacionismo. Así se explicaría el temor de sus personajes hacia un exterior regido por la incertidumbre y el riesgo, al igual que su renuencia a abandonar unos espacios interiores (que aspiran al aislamiento) en los que se cobijan de ese amenazante exterior.

El peligro intangible es igualmente vinculado por parte de dos personajes con la amenaza atómica vigente en la época de realización del filme (la crisis de los misiles en Cuba de 1962 estaba todavía reciente) en sendos momentos del metraje. André (Antonio Casas) afirma: "Quizá un día alguien apretará un botón y todo el mundo vivirá como nosotros mientras fuera acecha una muerte invisible", mientras que Asilov (James Philbrook) asegura que su situación "es como vivir bajo la amenaza de un bombardero atómico". El filme explicita verbalmente su poder alegórico de manera reiterada, guiando la labor hermenéutica del enunciatario. Un nuevo ejemplo lo encontramos cuando André comenta: "Tal vez ese extraño sonido simbolice el lamento de los que perdieron su vida tras el tesoro", evidenciando una simbología alternativa para el grito de la criatura que les acosa. Asimismo, los diálogos contienen regulares alusiones a la Segunda Guerra Mundial (de la que son supervivientes algunos de los protagonistas), conflicto armado cuya mención podría referirse veladamente a la Guerra Civil española, como apunta Aguilar (1997, p. 606).

El guion justifica el irracional empeño de los personajes por hacerse con el tesoro enterrado en la cueva donde mora la criatura (afán que les lleva a arriesgar su vida) convirtiéndolo en un proyecto vital para los más provectos de ellos, al que llevan dedicando una parte importante de sus vidas. La avaricia, la avidez de riqueza, aparece como elemento constitutivo de la naturaleza humana. Frente a esa individualidad, se impone la colaboración entre los personajes (simbolizada con la división del mapa del tesoro en dos mitades, sin una de las cuales se convierte en inútil) para hacer frente al monstruo irrepresentable, que también podría ser leído, pues, como una especie de castigo moral de orden divino (en un intento por dotar de profundidad a una historia en exceso esquemática, el guion introduce periódicas referencias mitológicas en los diálogos que aluden, entre otras, a 
la leyenda del Vellocino de Oro) por la codicia de unos protagonistas guiados por el deseo de posesiones materiales (tesoro, automóvil). Todos ellos aspiran a algo, miran hacia el futuro, pero será el pasado lo que los aceche. "El pasado también es presente", sentencia Stavros (Francisco Piquer). En este sentido, la criatura prehistórica representa ese pretérito que parece perseguir a los protagonistas, como si su pasado albergara unos pecados de los que no logran liberarse - puede que en esa guerra (civil) a la que se alude veladamente-. ${ }^{12}$ La invisibilidad de la amenaza invitaría así a conjeturar (si el lector del texto decide aventurarse en esta libérrima senda interpretativa) sobre si esta reside en la mente de unos personajes con cargo de conciencia. No en vano, el sentimiento de culpabilidad es un signo configurador de los protagonistas del director -recordemos Angustia o Los peces rojos (1955).

\section{A modo de conclusión}

La esquiva fisicidad de la monstruosa amenaza que pone en riesgo la vida de los protagonistas ocasiona una anomalía representacional en la escritura fílmica. El dispositivo cinematográfico únicamente puede acceder a su representación indicial, a la mostración de los vestigios y huellas de su presencia (literales: las que deja la criatura sobre la harina) y de sus actos (la cámara paseándose entre los destrozos que ha efectuado en la cocina). Se efectúa así un subrayado de los mecanismos formales mediante los que opera la enunciación, que adquieren un inusitado protagonismo ante el vacío figurativo. Aunque su molde genérico remite al pasado, la de El sonido de la muerte es una escritura propia de la modernidad cinematográfica al evidenciar sus resortes fílmicos enunciativos. Si la escritura clásica construye un preciso mecanismo narrativo y formal que persigue la invisibilización y/o el borrado de las huellas enunciativas del proceso de producción, la escritura fílmica de Nieves Conde dirige la atención del espectador hacia ellas.

${ }_{12}$ De haberse ubicado la acción dramática en nuestro país, el páramo por el que se mueven los personajes bien podría haber sido testigo de un enfrentamiento bélico en dicha contienda fratricida. 


\section{Referencias bibliográficas}

Aguilar, C. (1997). El sonido del miedo. En J. Pérez Perucha (Ed.). Antología crítica del cine español (pp. 604-606). Madrid: Cátedra / Filmoteca Española.

Carroll, N. (2005). Filosofía del terror o paradojas del corazón. Madrid: Antonio Machado.

García Jiménez, J. (1993). Narrativa audiovisual. Madrid: Cátedra.

Herrero Cecilia, J. (2000). Estética y pragmática del relato fantástico: las estrategias narrativas y la cooperación interpretativa del lector. Cuenca: Ediciones de la Universidad de Castilla-La Mancha.

Higueras Flores, R. (Ed.)(2015). Cine fantástico y de terror español. De los orígenes a la edad de oro (1912-1983). Madrid: T\&B.

Lenne, G. (1974). El cine fantástico y sus mitologías. Barcelona: Anagrama.

Ocampo Ramírez, G. I. (2013). De la monstruosidad a la alteridad en la obra de Diane Arbus. Trilogía (8), 19-28.

Prédal, R. (1970). Le cinema fantastique. Paris: Seghers.

Todorov, T. (1980). Introducción a la literatura fantástica. México: Premia. 